OPEN ACCESS

Edited by:

Mark A. Elgar.

The University of Melbourne, Australia

Reviewed by:

Elise Huchard,

UMR5554 Institut des Sciences de

l'Evolution de Montpellier

(ISEM), France

Klaudia Witte,

University of Siegen, Germany

*Correspondence:

Blake Carlton Jones

bjones@bio.fsu.edu

Specialty section:

This article was submitted to

Social Evolution

a section of the journal

Frontiers in Ecology and Evolution

Received: 20 July 2019

Accepted: 30 September 2019

Published: 18 October 2019

Citation:

Jones BC and DuVal EH (2019)

Mechanisms of Social Influence: A Meta-Analysis of the Effects of Social Information on Female Mate Choice

Decisions. Front. Ecol. Evol. 7:390.

doi: $10.3389 /$ fevo.2019.00390

\section{Mechanisms of Social Influence: A Meta-Analysis of the Effects of Social Information on Female Mate Choice Decisions}

\author{
Blake Carlton Jones* and Emily H. DuVal \\ Department of Biological Sciences, Florida State University, Tallahassee, FL, United States
}

Social learning about mate choices is taxonomically widespread, and is a potentially important mechanism of social evolution that may affect the strength of sexual selection in a population. We used a meta-analytic approach to estimate the effect of mate-choice copying on reproductive decisions. We evaluated effect sizes across 103 experiments from 40 studies that experimentally measured female mate-choice copying in non-human animals representing Arachnida, Insecta, Malacostraca, Aves, and Actinoperygii. Our goals were to quantify the magnitude of the effect of this form of social influence, and the extent to which it is modified by observer experience, model age relative to the observer, attractiveness of prospective mates, and testing conditions (laboratory vs. free-living). Across all studies, females that observed others choosing a male were on average 2.71 times more likely to mate with that male, or with a phenotypically similar individual, compared to females with no social information (odds ratio 95\% credible interval: 1.60-4.80). After corrected for publication bias, this effect remained significant (corrected odds ratio: 1.92, 95\% credible interval 1.13-3.40). We found little evidence for phylogenetic effects in the occurrence of mate-choice copying. Indeed, studies herein present evidence for mate-choice copying in a broad cross-section of species, but also report exceptions in sister taxa. Social information from observed mate choices of others had a considerably stronger effect on mate choice in free-living subjects than in captive individuals. Inexperienced (virgin) females were more likely to copy mate choices than were experienced females, but the relative age of the model was unrelated to whether copying occurred. Finally, females were more likely to copy the mate choices of others when social information counteracted the observing female's personal or genetic mating preference. We note the need for increased taxonomic representation in tests of mate-choice copying, given the robust demonstration of effects in taxa studied to date. Such broader information will provide additional insight to the drivers of the differences identified here in tendency to copy mate choices of others.

Keywords: cultural inheritance, Drosophila, mate-choice behavior, mate-choice copying, sexual selection, social learning, meta-analytic, Poecilia 


\section{INTRODUCTION}

One of the major benefits of living in social groups is access to information. Individuals can employ social information to recognize appropriate habitats, food items, and mates, thereby navigating some of the most important decisions facing an animal (Galef and Giraldeau, 2001; Danchin et al., 2004). When individuals use information gleaned from observing conspecifics (Hoppitt and Laland, 2008), they can reduce decision time, time to discover scarce resources, and costs of assessing competing choices (Valone and Templeton, 2002; Lee et al., 2016). In the context of mate choice, the extent to which animals change their mate choices in response to the behavior of others can influence the strength and dynamics of sexual selection in a population (Wade and Pruett-Jones, 1990; Verzijden et al., 2012). As such, socially mediated mate choices can modify the course of evolutionary change.

Female mate-choice copying is a type of social learning that occurs when a female's likelihood of mating with a male is influenced by the apparent choices of other females. Early consideration of this phenomenon suggested copying may be a factor in the high reproductive skew among lekking male sage grouse (Centrocercus urophasianus; Wiley, 1973) and white-bearded manakins (Manacus manacus; Lill, 1974), but the occurrence of mate-choice copying was first demonstrated experimentally in a captive population of Trinidadian guppies (Poecilia reticulata; Dugatkin, 1992). Regular reviews in the subsequent decades indicate the sustained interest in mate-choice copying and its implications for sexual selection (Gibson and Höglund, 1992; Nordell and Valone, 1998; Vakirtzis, 2011; Witte et al., 2015; Varela et al., 2018). Mate-choice copying occurs in a wide array of organisms, from humans (Waynforth, 2007; Gouda-Vossos et al., 2018; Homo sapiens) to Schizocosa wolf spiders (Fowler-Finn et al., 2015), including in animals that lack complex cognitive abilities or social systems (Danchin et al., 2018). Given the apparent prevalence and importance of matechoice copying, we aimed to assess the magnitude of its effects as well as the factors that influence this phenomenon.

Theoretical treatments predict that mate-choice copying should be favored in situations where information is limited, or when choice is costly (Gibson and Höglund, 1992; PruettJones, 1992). The perspective that mate-choice copying serves as a mechanism to reduce observer uncertainty has received the strongest support to date (Vakirtzis, 2011). In taxonomically diverse animals, and in a variety of situations other than mate choice, social information has a greater influence when observers are young or otherwise inexperienced, for example when they encounter new environments or when a preferred choice is unavailable (Galef and Giraldeau, 2001; Valone and Templeton, 2002; but see Loukola et al., 2012). In mate-choice copying, this suggests that young or sexually inexperienced females should be more likely to copy the mate choices of others, as has been reported in guppies and wolf spiders (Dugatkin and Godin, 1993; Fowler-Finn et al., 2015).

Empirical studies to date have also demonstrated that all social information is not equal. Observers of many species seem to pay more attention to information from certain individuals. For example, captive chimpanzees (Pan troglodytes) were more likely to learn a novel foraging behavior form socially dominant and knowledgeable individuals (Kendal et al., 2015), and humans are more likely to copy mate choices of more desirable demonstrators (Gouda-Vossos et al., 2018). In addition to being influenced by characteristics of observers, mate-choice copying decisions may vary based on characteristics of the model females.

Relative quality of choices is also a factor that can influence the degree to which individuals use social information in decision making. For example, in ocellated wrasse (Symphodus ocellatus), mate-choice copying is more likely to occur when model females are observed with unattractive males rather than with attractive ones (Alonzo, 2008). Across taxa, approaches to quantifying mate-choice copying have differed in whether an observer's innate preference was incorporated into measures of the influence of social information. Studies employing random enhancement increase attractiveness of a particular male using signals of other females' preferences. Enhancement studies usually choose the male at random for the addition of the conspecific cue and assume that without that information females would be equally likely to choose between the two males (Dugatkin, 1992; Germain et al., 2016). In studies that incorporate "reversals," experimenters first identify a female's preferred mate, either by directly quantifying preference for one of two competing males (Dugatkin and Godin, 1992), or by using prior evidence of genetically determined mating preferences (Dugatkin, 1996, 1998). They then quantify whether providing social cues in favor of the non-preferred male could change expressed mate choices. Because the personal or genetic preference of a female is known, reversal studies may produce less ambiguous results about the strength of matechoice copying.

Given the difficulty of monitoring female movements and information in the wild, mate-choice copying has been studied almost exclusively in laboratory situations. However, work in wild populations also indicates that copying occurs outside of the lab. Some studies have manipulated behavior in the wild in ways comparable to lab experiments, by adding model females or other signals of mate preference to free-living but stationary males, and quantifying change in the behavior of other females that results (Höglund et al., 1995; Stiver and Alonzo, 2010). In other cases, mobile males have been restrained in tanks, with model females placed in close proximity, as is commonly done in laboratory trials, but unrestrained females were allowed to approach the restrained males under otherwise natural conditions (Witte and Ryan, 2002; Godin and Hair, 2009). Given that mate-choice copying is an ecologically relevant phenomenon expected to influence the behavior and ultimate fitness of animals, we aimed to quantify if our understanding of mate-choice copying in the laboratory is comparable to how it functions in nature.

While tests of mate-choice copying commonly quantify influence on choice of specific males, recent work demonstrates that females learn general characteristics of target males and copy choices of phenotypes, rather than of specific individuals (Witte and Noltemeier, 2002; Godin et al., 2005; Danchin et al., 2018). This distinction is important for understanding how 
broadly and rapidly mate-choice copying could affect patterns of sexual selection in real populations. When model females were associated with males of a specific phenotype of a visible morphology, observers demonstrated a generalized preference for the same phenotype rather than a preference for the specific individual male (Kniel et al., 2015; Dagaeff et al., 2016; Nöbel et al., 2018). For example, when female Drosophila observed others mating with males covered in either pink or green powder, they formed a preference for these novel, artificially generated color phenotypes when they encountered them in different males, even when new males differed in other obvious phenotypes (Danchin et al., 2018). What's more, this phenotypespecific preference persisted over time, intensified after a 24 -h consolidation period, and was lost if females were treated with a protein synthesis inhibitor that prevented long-term memory formation (Danchin et al., 2018).

Given the potential importance of mate-choice copying in sexual selection, our goals in this study were to determine the magnitude of the effect of mate-choice copying across studies, and to test whether the strength of copying effects is modified by observer characteristics, demonstrator characteristics, and effects of differences in attractiveness among competing choices. We also tested whether the effect of mate-choice copying differed between captive and free-living systems. We used a metaanalytic approach that allowed us to control for non-independent data due to phylogenetic relationships, taxonomy, and multiple experiments conducted during the same study. We also assessed the level of heterogeneity in mate-choice copying effects. Finally, we tested for the occurrence and impact of publication bias in the study of mate-choice copying.

A recent review and meta-analysis of effects in studies of human mate-choice copying found that effects were strongest in females, and that both males and females rated prospective mates as more desirable when they were in the presence of more desirable models (Gouda-Vossos et al., 2018). Most human studies indirectly assess mating preferences, for example by having subjects rate the relative attractiveness of a person on a numeric scale, which is not easily combined with assessment metrics in non-human animals. Here we focused on female matechoice copying in non-human animals. While males of some species may copy the mate-choice of other males (Schlupp and Ryan, 1997; Witte and Ryan, 2002; Widemo, 2005), we focus here on females both because there have been relatively few studies on this phenomenon in males, and because the sexes may diverge in strategies employed in choosing mates. For example, males of some species avoid recently mated females, with whom chances of fertilization may be lower (White and Galef, 1999). Additionally, audience effects are often apparent, as when males reverse mating preferences in the presence of other males, arguably decoying others away from their preferred mates and reducing pre- or post-copulatory competition for fertilizations (Bierbach et al., 2011; Auld and Godin, 2015).

Our study is, to the best of our knowledge, the first meta-analysis of female mate-choice copying in non-human animals. This work aims to more clearly define the extent to which individuals pay attention to social information during mate choice.

\section{METHODS}

We conducted a meta-analysis of empirical studies quantifying mate-choice copying in non-human animals. We identified relevant studies using a topic search in Web of Science (ISI Thomas Reuters) specifying the search criteria as: TS $=$ [("mate choice" AND "copy") OR ("mate-choice" AND "copy*”) OR "mate-copy*” OR "mate copy*” OR "female* copy*”, targeting peer-reviewed research published between 1900 and May 2019. This returned a total of 356 publications. Of these, we excluded 102 human studies. We then filtered out 113 articles that were clearly not about mate-choice copying and 51 articles that lacked empirical data (e.g., reviews, theoretical models, or opinion papers). We also excluded 14 studies of the audience effect on male mate-choice behavior, in which males reverse apparent mating preferences in the presence of other males (Bierbach et al., 2011; Auld and Godin, 2015). We excluded nine studies that did not experimentally assess mate-choice copying directly or at all. We further excluded 24 studies that assessed mate-choice copying but did not determine individual choices. Finally, we excluded three studies quantifying male mate-choice copying because these studies identified audience effects (described above) on male behavior that are logically separate from selective pressures on female behavior. We were left with 40 empirical studies reporting 103 separate experiments that tested directly for female mate-choice copying (Figure 1).

\section{Extraction of Effect Sizes}

Studies considered for this meta-analysis quantified mate-choice copying by allowing an observer female to choose between two males, one of which was previously associated (e.g., via spatial proximity, courtship behavior, or copulation) with another female (i.e., the model). The choices of observers with the opportunity to mate-choice copy were compared to one of two types of controls: (1) observer females that did not witness the model female's choice, and thus did not have the opportunity to mate-choice copy $(n=43)$ or (2) an assumed $50 / 50$ odds that an observer would pick either of the two males in the absence of a mate-choice copying opportunity $(n=60)$. In both cases, we extracted effect sizes as odds ratios $(O R)$ with the following formula:

$$
O R=\frac{A D}{B C}
$$

$A$ is the number of female observers exposed to a model's choice that chose the same male or male phenotype. Similarly, $B$ is the number of observers exposed to a model's choice that did not copy it. $C$ is the number of control females (i.e., females that did not witness the model's choice) that made the same choice as the model. $D$ is the number of controls that did not choose the same as the model. We used the natural log of the $O R[\ln (O R)]$ to normalize the distribution of the data. We back transformed all model estimates and credible intervals to $O R$ to more intuitively report the results. We calculated variance $\left[V_{\ln (O R)}\right]$ and sampling error $\left[S E_{\ln (O R)}\right]$ of the $\ln (O R)$ of each 


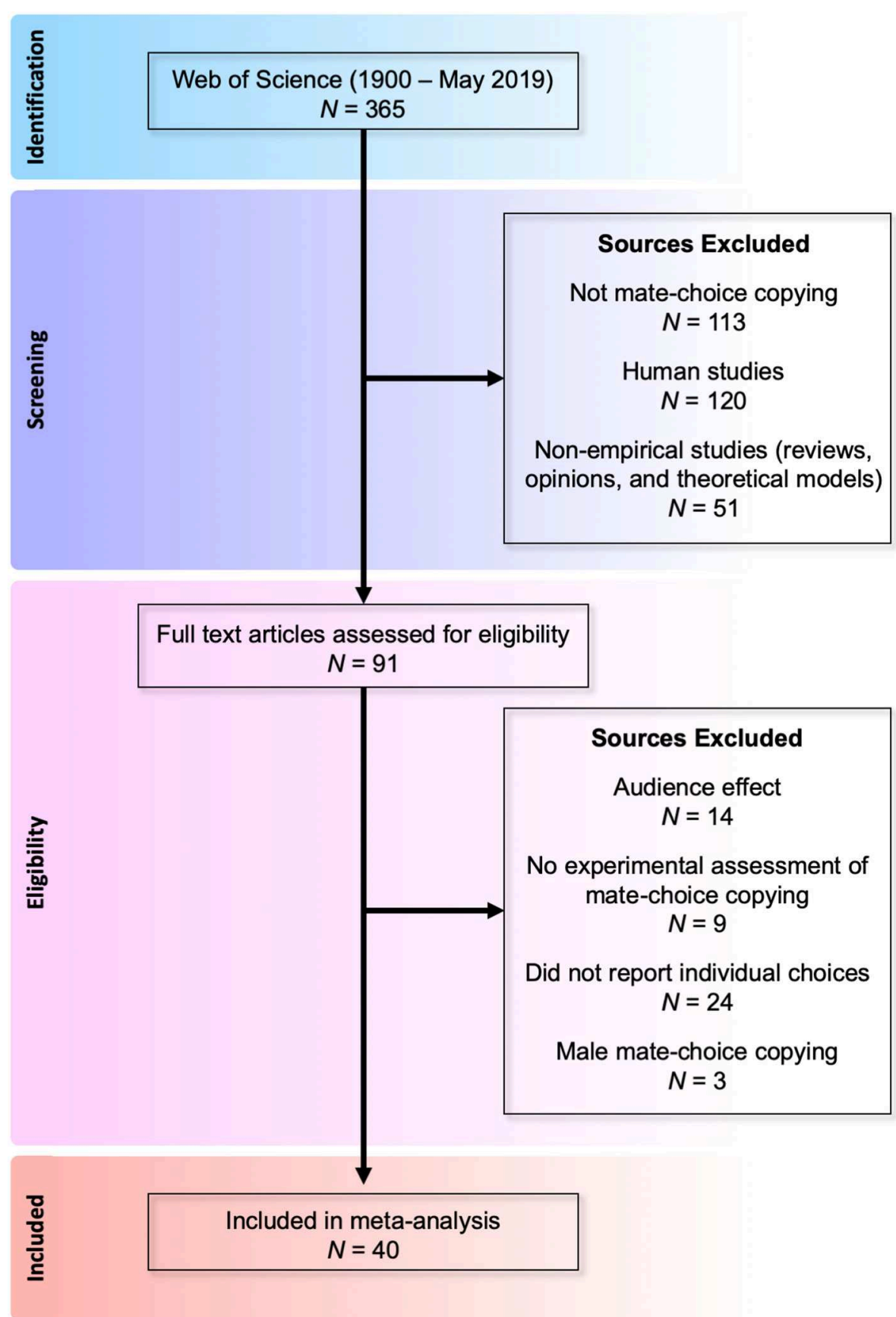

FIGURE 1 | Flow diagram of selection process for female mate-choice studies.

experiment with the follow equations:

$$
\begin{array}{r}
V_{\ln (\mathrm{OR})}=\frac{1}{A}+\frac{1}{B}+\frac{1}{C}+\frac{1}{D} \\
S E_{\ln (\mathrm{OR})}=\sqrt{V_{\ln (\mathrm{OR})}}
\end{array}
$$

The parameters $A-D$ are the same as described above. Note that as variance for $\ln (O R)$ is determined solely on the sample size of each group, experiments with small samples sizes will have large sample errors. Some studies did not use a control group per se, but rather assumed 50:50 odds of choosing either male. In these cases, we calculated $O R, V_{\ln (O R)}$, and $S E_{\ln (O R)}$ using hypothetical values for $C\left(C_{h}\right)$ and $D\left(D_{h}\right)$ based on the same number of individuals exposed to the model choice and the $50 \%$ probability assumption (Equation 4).

$$
C_{h}=D_{h}=\frac{A+B}{2}
$$




\section{Coding Moderators of Mate-Choice Copying Behavior}

We identified four key factors that we hypothesized modify the strength of mate-choice copying effects and that we were able to assess for all studies in our sample: observer experience, model female age, male attractiveness, and testing conditions (i.e., free-living vs. captive).

Observer experience was categorized as virgin (females with no prior sexual experience) or non-virgin. In this latter condition, we assumed that females housed in mixed-sex groups were likely non-virgins unless the author(s) explicitly stated that mixed groups were held at environmental parameters to suppress breeding condition development. It is possible that mixed-sex groups included both virgin and non-virgin individuals.

Model female age was relative to the observer's age and categorized as "older" or "same or younger." Size was reasonably used as a proxy for age in studies of fish, such as guppies, that exhibit indeterminate growth. Only two in our set of 103 retained experiments used a model that was younger relative to the female observer (Dugatkin and Godin, 1993; Vukomanovic and Rodd, 2007).

Male attractiveness was estimated by whether the experiment provided social information favoring the relatively less attractive of two males. Many experimental protocols used a reversal paradigm, in which a female was paired with a male previously rejected by the observer. We considered these rejected males to be less attractive in the eyes of the observer but nonetheless "chosen" by the model during copying trials. A subset of studies used previously identified mating preferences of females from the study population to define unattractive male characteristics (e.g., dull male guppies from a population in which females prefer bright orange males, Dugatkin, 1998). In experiments in which social information did not favor less attractive males, model females were either paired with a randomly chosen male (usually from a phenotypically matched pair of males) or, more rarely, allowed to choose independently. In these experiments, males paired with a model were considered no more or less attractive, on average.

Finally, we parameterized testing conditions as whether experiments were conducted in captivity or in a natural setting with free-living individuals. Our captive category included both lab-reared individuals, and those that were wild-caught and tested in the laboratory. Extracted data used in this meta-analysis are provided in the Supplementary Materials (Table S1).

\section{Meta-Analysis}

We conducted a meta-analysis of results from mate-choice copying studies using univariate-response Bayesian generalized linear models with Markov chain Monte Carlo (Hadfield, 2010; Hadfield and Nakagawa, 2010) in the programing language R, version 3.6.0 (R Core Team, 2019) and MCMCglmm package (Hadfield, 2010). Under this framework, we compared a randomeffects model to a mixed-effects model (i.e., meta-regression; Hedges and Vevea, 1998). The random-effects model included a matrix of phylogenetic distances, and random effects of study and species (see below for full justification). The mixedeffects model included those random effects and also our four hypothesized explanatory factors described above (observer experience, demonstrator age, male attractiveness, and testing conditions). These models did not assume a single true effect size for mate-choice copying. Rather, they assumed that each individual study had a true effect size and thus estimated the mean of the distribution of effect sizes. The mixed effects models also weighted individual effect sizes by the inverse of $S E_{l n(O R)}$, so that experiments with larger sample sizes had a stronger influence on the parameter estimates. First, we quantified heterogeneity in our random-effects model and then the mixed-effects model (Higgins and Thompson, 2002; Higgins et al., 2003) to determine how well-moderators (i.e., explanatory factors) accounted for effect size variation among experiments. Second, we compared the fit of these two models using Deviance Information Criterion (DIC; Spiegelhalter et al., 2014). Smaller DIC values indicate a better overall fit of the model to the data. Third, we determined the overall mean effect size of mate-choice copying and tested the significance of explanatory moderators. Lastly, we assessed possible publication bias (Sutton, 2009; Nakagawa and Santos, 2012).

\section{Phylogenetic and Taxonomic Meta-Analytic Model}

Meta-regressions are particularly useful in ecology and evolution, as they can accommodate non-independent data due to phylogenetic relationships among taxa and when individual studies each produce multiple effect sizes (Nakagawa and Santos, 2012). Controlling for phylogeny in comparative analyses is essential (Freckleton et al., 2002; Blomberg et al., 2003), and increasingly advocated in biological meta-analyses (Adams, 2008; Lajeunesse, 2009; Hadfield and Nakagawa, 2010; Nakagawa and Santos, 2012). However, our dataset included 17 species that spanned five classes within Chordata and Arthropoda. As such, a tree that was fully resolved to the species level was not obtainable. Therefore, we combined phylogenetic and multilevel taxonomic approaches as described by Hadfield and Nakagawa (2010). The phylogenetic portion of our mixed meta-analytic model uses the "animal model" framework (Henderson, 1976) to construct a phylogenetic relatedness matrix and to account for evolutionary divergence times between any two taxa (Lynch, 1991; Pagel, 1999). The relatedness matrix was derived from an ultrametric tree obtained from TimeTree.org (Kumar et al., 2017) and fully resolved to the family level of our 17 unique species (13 families). The phylogenetic control was combined with a taxonomic analysis by including species identity as a random effect. We also included study as a random effect, as many publications had multiple experiments with associated effect sizes.

\section{Posterior Means and Moderators of Mate-Choice Copying}

We determined the overall effect size of female mate-choice copying using a univariate-response Bayesian generalized linear mixed-effects model with Markov chain Monte Carlo (BMM; Hadfield, 2010; Hadfield and Nakagawa, 2010). We quantified the posterior mean of the overall $O R$ and $95 \%$ credible interval 
of mate-choice copying as well as the $95 \%$ prediction interval (Riley et al., 2011). Credible intervals that did not cross an $O R$ of 1 were considered statistically significant ( $O R$ of 1 equals a $50 \%$ probability). We also include our four moderators of mate-choice copying as fixed effects and calculated the change in posterior mean $O R(\triangle O R)$ between their levels (e.g., virgin vs. non-virgin observers) as well as the $95 \%$ credible interval. We considered $\triangle O R$ s to be statistically significantly different if their credible intervals did not overlap. Further, we calculated the mean $O R$ and associated 95\% credible interval of each level of the moderators using the moderator estimates weighted by the inverse of $S E_{\ln (O R)}$.

\section{Measuring Heterogeneity}

Heterogeneity, or the degree of inconsistencies across studies, is a vital component of meta-analytic procedures and is expected to be high in ecology and evolution meta-analyses (Senior et al., 2016). We quantified heterogeneity in OR among different studies and species by calculating the percent of variance explained by each random effect. Traditional measures of heterogeneity in meta-analysis (e.g., $Q, I^{2}$ ) were not originally developed for use in models with multiple random effects (Higgins and Thompson, 2002; Nakagawa and Santos, 2012). Here we use a method developed by Nakagawa and Santos (2012) to measure the heterogeneity within a given random effect as a portion of the total heterogeneity based on the formulation of $I^{2}$ (Higgins and Thompson, 2002). The total variance $\left(\sigma_{t}^{2}\right)$ of our phylogenetic-taxonomic mixed meta-analytic model can be written as the sum of all the random components (Equation 1)

$$
\sigma_{t}^{2}=\sigma_{p}^{2}+\sigma_{a}^{2}+\sigma_{s}^{2}+\sigma_{m}^{2}+\sigma_{e}^{2}
$$

Variance parameters include those attributed to phylogenetic effects $\left(\sigma_{p}^{2}\right)$, species effects $\left(\sigma_{a}^{2}\right)$, study effects $\left(\sigma_{s}^{2}\right)$, individual experiment sample error $\left(\sigma_{m}^{2}\right)$, and residual error $\left(\sigma_{e}^{2}\right)$. We were then able to calculate the proportional amount of heterogeneity at the species level (Equation 6) and the study level (Equation 7).

$$
\begin{aligned}
& I_{a}^{2}=\frac{\sigma_{a}^{2}}{\sigma_{t}^{2}} \\
& I_{s}^{2}=\frac{\sigma_{s}^{2}}{\sigma_{t}^{2}}
\end{aligned}
$$

We also calculated the phylogenetic signal $\left(H^{2}\right)$ with the following equation (Lynch, 1991):

$$
H^{2}=\frac{\sigma_{p}^{2}}{\left(\sigma_{p}^{2}+\sigma_{a}^{2}+\sigma_{s}^{2}+\sigma_{m}^{2}\right)}
$$

A $H^{2}=0$ indicates that phylogenetic relatedness among taxa does not explain effect size variation, whereas $H^{2}=1$ indicates that the effect sizes of taxa are completely proportional to their phylogenetic relationships.

\section{Publication Bias}

Publication bias is an important concern in meta-analyses, as it can influence the validity of results (Rosenthal, 1979; Sutton,
2009). Therefore, we assessed possible publication bias using a modified Egger's regression as described by Nakagawa and Santos (2012), in which measures of precision are compared to corresponding meta-analytic residuals. Unlike the weighted effect sizes, the associated residuals are independent of one another and not influenced by heterogeneity (Nakagawa and Santos, 2012). We corrected for publication bias using the "trim and fill" method (Duval and Tweedie, 2000) using the R package meta (Schwarzer, 2007), which removes small studies and imputes new effect sizes of hypothetical experiments to restore symmetry in the funnel plot (Duval, 2005). Asymmetry can also be due to heterogeneity in the data, and thus any correction would erroneously bias the true mean effect size (Peters et al., 2007). Therefore, we used meta-analytic residuals described above to determine the presence of publication bias instead of weighted effect sizes as suggested by Nakagawa and Santos (2012).

\section{RESULTS}

We calculated 103 effect sizes from 40 published studies of mate-choice copying that met our selection criteria. The mean posterior $O R$ for mate-choice copying was $2.71(95 \%$ credible interval 1.60-4.80; Figure 2). In other words, given a dichotomous choice, females were on average 2.71 times more likely to choose a particular male, or male of a similar phenotype, if she observed another female choosing him first, compared to females with no social information. The range of likely values for the overall mean effect of mate-choice copying did not cross the null value $(O R=1$, indicating $50 \%$ probability of such a choice). Therefore, we considered the overall mean effect of mate-choice copying statistically significant. The $95 \%$ prediction interval of effect sizes, which more fully describes the range of possible effect sizes within any single study rather than just the mean effect size across all studies, was 0.31 to 22.75 (Figure 2; see discussion for further interpretation).

\section{Phylogenetic Effects}

Our analysis included experiments on 17 species from 13 different families, representing three classes of arthropods and two classes of vertebrates. Our meta-analytic model accounted for phylogenetic relatedness by incorporating divergence times at the family level. We found little evidence for a phylogenetic signal in mate-choice copying $\left(H^{2}=0.06\right.$, Table $\left.\mathbf{1}\right)$.

\section{Study and Species Heterogeneity}

Our initial random meta-analytic model indicated low heterogeneity among individual studies $\left(I_{s}^{2}=0.01\right)$ but substantial heterogeneity among species $\left(I_{a}^{2}=0.75\right.$, Table 1) producing a high level of overall heterogeneity in our data set $\left(I_{a}^{2}+I_{s}^{2}=0.76\right.$, Table 1; Higgins et al., 2003). In contrast, the inclusion of explanatory factors (i.e., in the mixed-effect metaanalytic model), explained the vast majority of heterogeneity previously attributed to the level of species $\left(I_{a}^{2}=0.07\right.$, Table 1$)$. Further, DIC values indicated that the mixed-effects model was a slightly better fit given our dataset compared to the random effects model (Table 1). However, models that differ in DIC value 


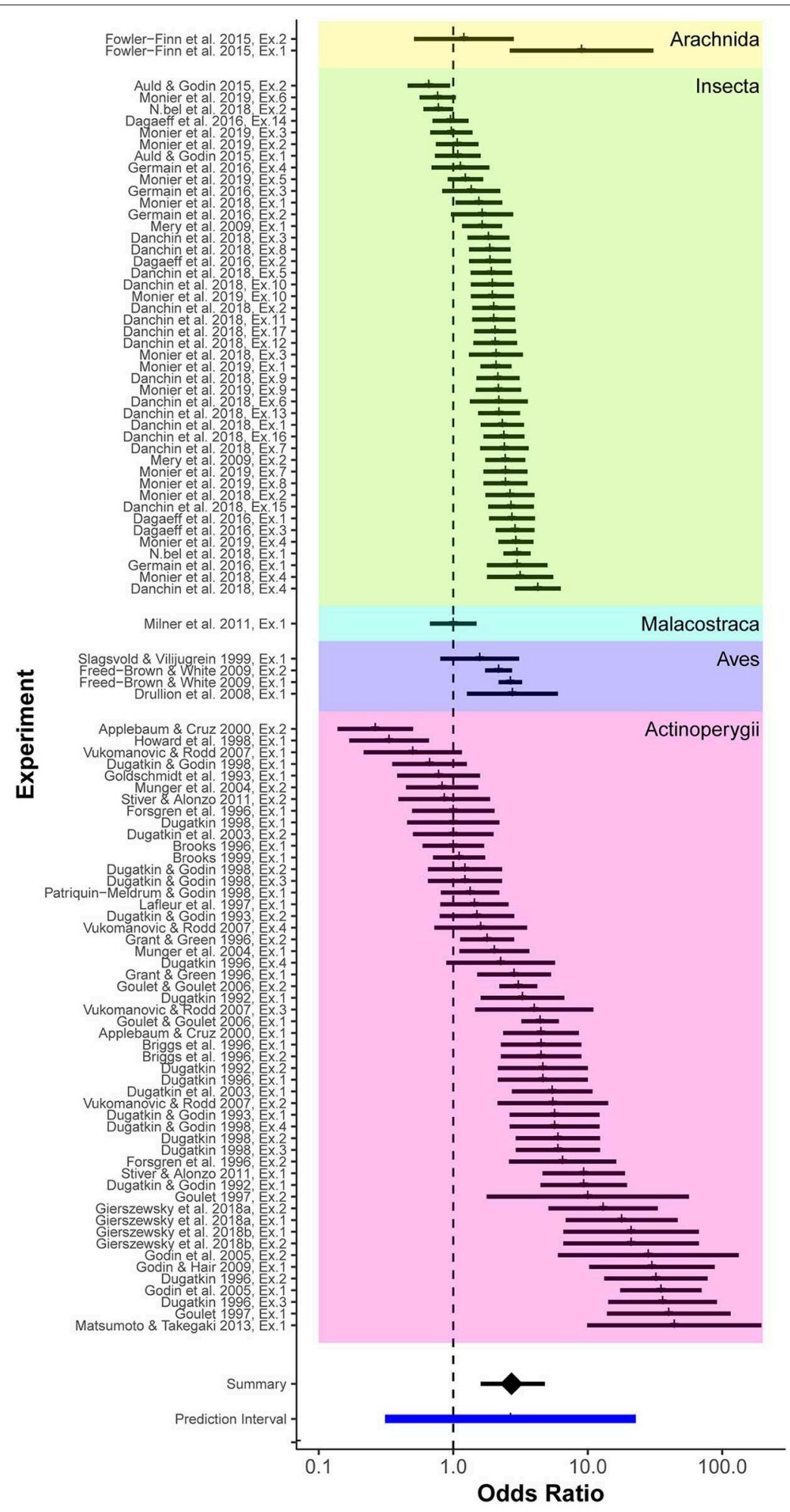

FIGURE 2 | Forest plot of effect sizes (odds ratios) from all considered studies, grouped taxonomically. Colored groupings represent taxonomic divisions by class. From top to bottom these are: Arachnida, Insecta, Malacostraca, Aves, and Actinoperygii. Effect sizes for individual experiments are indicated as vertical tick marks along with associated sampling errors (horizontal bar). The overall posterior mean effect size, derived from the mixed-effects model that accounted for phylogenetic distance, species, and study (Table 1), was 2.71, indicating that an average female receiving positive social information about a prospective mate was 2.71 times more likely to mate with that male compared to females with no social information. 
TABLE 1 | Heterogeneity explained by random effects in competing meta-analytic models.

\begin{tabular}{|c|c|c|c|c|c|c|}
\hline \multirow{2}{*}{$\begin{array}{l}\text { Meta- } \\
\text { analytic } \\
\text { model }\end{array}$} & \multirow{2}{*}{$\begin{array}{l}\text { Fixed } \\
\text { effects }\end{array}$} & \multirow[t]{2}{*}{ DIC } & \multicolumn{3}{|c|}{ Percent heterogeneity } & \multirow{2}{*}{$\begin{array}{c}\text { Phylogenetic } \\
\text { signal }\left(\mathbf{H}^{2}\right)\end{array}$} \\
\hline & & & $\begin{array}{c}\text { Study } \\
\left(I_{s}^{2} * 100\right)\end{array}$ & $\begin{array}{l}\text { Species } \\
\left(I_{a}^{2} * 100\right)\end{array}$ & Total & \\
\hline Random & - & 278.24 & 0.7 & 75.0 & 75.7 & 0.05 \\
\hline Mixed & $\begin{array}{l}\text { Model } \\
\text { female age, } \\
\text { male } \\
\text { attractiveness, } \\
\text { observer } \\
\text { experience, } \\
\text { testing } \\
\text { conditions }\end{array}$ & 276.65 & 0.8 & 7.4 & 8.2 & 0.06 \\
\hline
\end{tabular}

A model containing only random effects was compared to one including four fixed effects in addition to the same random effects of study, species, and phylogenetic relatedness. See Table 2 for further information and parameter values for listed fixed effects. Study identity was defined at the level of individual publications and was included to account for non-independence when multiple effect sizes were taken from the same paper. Species was included as a random effect to control for repeated measures at this taxonomic level. Phylogenetic signal was parameterized as a phylogenetic relatedness matrix (see methods) to account for non-independence due to taxonomic divergence times. Models were compared by deviance information criterion (DIC).

by $<5$ are typically interpreted to be equivalent (Spiegelhalter et al., 2014).

\section{Moderators of Mate-Choice copying Observer Experience}

Among the experiments we assessed, observer females that had no previous experience mating (i.e., virgins) were significantly more likely to copy the mate-choice of an observed same-sex conspecific compared to non-virgin individuals $(\triangle O R=1.53$, $95 \%$ credible interval $=0.16-2.94, P=0.03$, Table 2, Figure 3, Figure S3). When virgin females saw another female choose a male, they were 3.2 times more likely to mate with that male (posterior mean $O R=3.21,95 \%$ credible interval $=2.48-4.16$ ). In contrast, females with previous mating experience were 1.7 times more likely to choose a male after he was favored by this type of social information (posterior mean $O R=1.68,95 \%$ credible interval $=1.22-2.32$ ).

\section{Model Age}

Females were no more likely to copy the mate choice of an older female than that of females their own age $(\triangle O R=-0.10,95 \%$ credible interval $=-1.68-1.59, P=0.88$, Table 2, Figure 3).

\section{Male Attractiveness}

We found that observer females were more likely to copy the choice of a model female when the model was paired with a less attractive male compared to a random male $(\triangle O R=3.79$, $95 \%$ credible interval $=1.52-6.64, P=0.004$, Table 2, Figure 3, Figure S1). After females observed a model associating with a randomly chosen male, they were approximately twice as likely to choose that mate in a subsequent trial (posterior mean $O R$ $=2.13,95 \%$ credible interval $=1.68-2.71)$. In contrast, after females saw a model choose a previously non-preferred male, they were nearly six times more likely to mate with that male
TABLE 2 | Fixed-effect estimates from the Bayesian hierarchical meta-analysis assessing strength of moderators hypothesized to affect the occurrence of mate-choice copying.

\begin{tabular}{|c|c|c|c|c|}
\hline Parameter & Estimate & Lower $95 \% \mathrm{Cl}$ & Upper $95 \%$ Cl & pMCMC \\
\hline Intercept & 1.13 & 0.65 & 1.02 & 0.65 \\
\hline $\begin{array}{l}\text { Observer experience } \\
\text { (virgin) }\end{array}$ & 1.53 & 0.16 & 2.94 & 0.03 \\
\hline $\begin{array}{l}\text { Model female age } \\
\text { (model older) }\end{array}$ & -0.10 & -1.68 & 1.59 & 0.88 \\
\hline $\begin{array}{l}\text { Mate attractiveness } \\
\text { (less attractive) }\end{array}$ & 3.79 & 1.52 & 6.64 & 0.004 \\
\hline $\begin{array}{l}\text { Testing conditions } \\
\text { (free-living) }\end{array}$ & 12.10 & 4.95 & 23.47 & $<0.001$ \\
\hline
\end{tabular}

The analysis included random effects of phylogenetic relatedness, species, and study. Factors considered were mating experience of the observer (virgin vs. non-virgin); age of the model female relative to the observer (whether the female shown associating with a male in the demonstration phase of the experiment was older vs. younger or the same age as the observer); mate attractiveness (whether females were provided with copying information that systematically favored their non-preferred male); and the testing conditions (whether the subjects were captive or free-living during trials). The comparison level of each categorical variable is shown in brackets after the parameter. The effective sample size for each parameter was 1,000. Ninety-five percent $\mathrm{Cl}$ indicates the 95\% credible interval. pMCMC is the Markov Chain Monte Carlo estimate of significance for that effect in the model. Variance due to each random effect is shown in Table 1. Bold text and values indicate statistical significance at $P<0.05$.

in subsequent trials (posterior mean $O R=5.92,95 \%$ credible interval $=4.22-8.32$, Figure 3, Figure S1). Non-preferred males in this analysis included those identified from known genetic preferences and from pre-tests of observer preference, and so we wondered whether these situations might elicit different degrees of copying. However, a post-hoc analysis found no statistical difference in the strength of mate-choice copying between these two groups $(\triangle O R=4.65,95 \%$ credible interval $=-1.67-24.48, p$ $=0.25 ; n=24$ effect sizes from studies where social information favored a non-preferred male).

\section{Testing Conditions}

Mate-choice copying had a stronger effect under free-living conditions compared to captive testing of both captive-bred and wild-caught individuals $(\triangle O R=12.10,95 \%$ credible interval $=4.95-23.47, P<0.001$ Table 2, Figure 3, Figure S2). When free-living females saw another female with a male, they were approximately 14 times more likely to subsequently mate with that male (posterior mean $O R=14.40,95 \%$ credible interval $=8.28-25.07$ ), while captive females were only 2.3 times more likely to do so (posterior mean $O R=2.31,95 \%$ credible interval $=1.60-3.32$ ).

\section{Publication Bias}

We found evidence for the presence of publication bias in matechoice copying studies, as the intercept of a modified Eggers regression was significantly different than zero (intercept $+\mathrm{SE}$ : $0.81+0.38, t=2.11, p=0.037$, Figure 4). This indicates that the mean and credible interval of effect sizes may be inflated by the under-reporting of null results. We assessed the impact of this publication bias using the trim and fill test (Duval and Tweedie, 2000), which added 25 data points to our original 103 


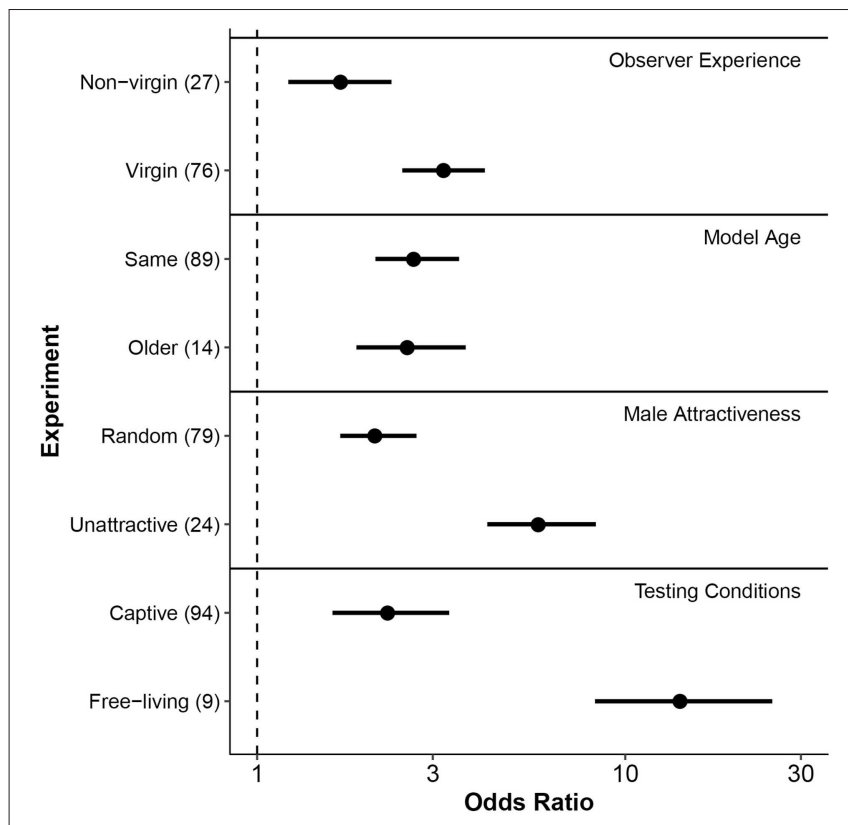

FIGURE 3 | Forest plot of posterior mean effect sizes (odds ratios) of each moderator level hypothesized to affect mate-choice copying. Horizontal lines associated with points indicate 95\% credible intervals of the mean odds ratio. Levels of each fixed effect ( $y$-axis) are grouped by moderator type, shown at right. Numbers in parentheses following each level indicate the number of effect sizes included from experiments that met those conditions. The dashed vertical line indicates an odds ratio of 1 , equivalent to a 50/50 likelihood of mating with a male after observing another female choose that male, or a phenotypically similar individual. X-axis is on a log10 scale. Model female age refers to the model's age relative to the observer female. In many cases, differences noted referred to relative size rather than age per se, as size is a commonly used proxy of age in fish with indeterminate growth. and provided a $\ln (O R)$ estimate adjustment of -0.345 . Adjusting our original mean estimates to account for publication bias reduced the size of the mean effect of mate-choice coping, but the effect remained statistically significant $(O R=1.92,95 \%$ credible interval 1.13-3.40).

\section{DISCUSSION}

Our meta-analysis indicated that female mate-choice copying is a widespread and influential phenomenon. Across all studies assessed, females were on average 2.7 times more likely to choose a particular mate if they received social information favoring that male, compared with females that did not receive such social information. The significant tendency for matechoice copying to occur remained evident after publication bias was taken into account. We found that mate-choice copying was more likely to occur when the females receiving social information lacked mating experience, or when they received new information about males that were initially "unattractive." However, we found no consistent support for the idea that observer females preferentially attend to the mating decisions of older females. Unexpectedly, there was a strong effect of testing conditions on whether mate-choice copying occurred; effects

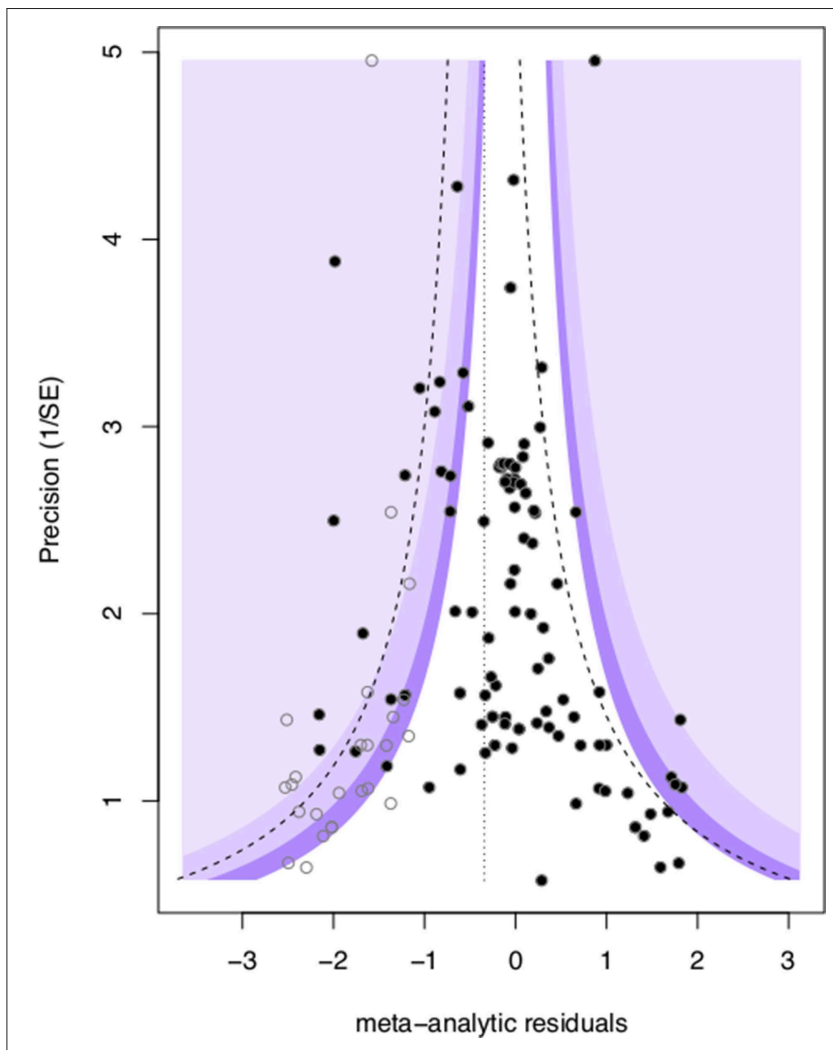

FIGURE 4 | Visualization of publication bias via a contour funnel plot showing meta-analytic residual In (OR) vs. corresponding precision $\left(1 / S E_{\ln (O R)}\right.$, black circles). The plot also illustrates the trim and fill "missing" data points (open circles) required to restore funnel symmetry. The dotted line represents the In $(O R)$ adjustment which was applied to the mean of the meta-analytic residuals to correct for publication bias.

reported from free-living animals were considerably stronger than those from captive individuals. The prediction interval for the overall effect of mate-choice copying crossed 1 on the OR scale, indicating that evidence for mate-choice copying may not always be present depending on the context and species. In other words, our analysis included some experiments in which matechoice copying did not occur, and indeed both copying and noncopying strategies have been theoretically predicted to persist in the same population (Dubois et al., 2011). The situations in which mate-choice copying does and does not influence observed mating choice therefore are an interesting area for further research.

As predicted theoretically, we found that females with no mating experience (virgins) were more likely to copy mate choices than were non-virgin females or mature females of unknown sexual history. Social information should logically be most useful to individuals who lack complete information for decision-making, and the disproportionate occurrence of matechoice copying by virgins supports this assumption. Despite studies supporting the idea that females pay more attention to social information from older individuals (Dugatkin and Godin, 1993; Amlacher and Dugatkin, 2005), we found no overall 
trend for increased occurrence of mate-choice copying when model females were older than observers. In most cases, model females were age- or size-matched with observer females, and mate-choice copying was as likely to occur in such cases as in situations when the observer was older or larger. However, we did not have enough information to assess other types of asymmetry between the observer and demonstrator females. For example, copying females may attend more to the behavior of familiar, healthy, attractive, or socially dominant conspecifics. In cases where species identity may be questionable, females may attend to information from conspecifics over that from heterospecifics (Hill and Ryan, 2006). These factors were not consistently assessed in the studies we considered here, and so were not included in the current analysis but represent interesting possibilities for future research into how model characteristics may influence observer choice.

Mate attractiveness modified the occurrence of copying. Positive social information had a relatively minor effect on mating behavior when it favored preferred mates, but substantially increased the likelihood that females chose nonpreferred males, as was demonstrated in field tests of ocellated wrasse mate choice (Alonzo, 2008). One methodological consideration that could influence the accuracy of our estimate for effects of mate attractiveness is the calculation of null expectation. We classified relative attractiveness of males as whether or not the experiment provided social information that systematically favored the least preferred male. In such situations, the ideal baseline comparison group is a set of females tested to quantify their likelihood of switching mates in a second trial in the absence of social information. We assumed a baseline of $50 / 50$ odds of switching when such information was not available. Females of some taxa have shown a tendency to switch mate choices in repeated trials. For example, a study of zebra finch copying found that females switched to spend more time near a previously non-preferred mate in second trials, whether or not that mate was seen with a model female (Doucet et al., 2004). This effect could lead to a bias in favor of the conclusion that matechoice copying was taking place. In future work, we recommend that studies investigating mate-choice copying not assume the null result is a 50:50 outcome, but instead explicitly test the baseline probability that females reverse mating preferences when repeatedly exposed to potential mates in the absence of social information.

Of all explanatory factors considered, testing condition had the strongest effect on the occurrence of mate-choice copying. Females were considerably more likely to copy mate choices when experiments tested free-living females rather than those in captivity. The vast majority of studies of mate-choice copying have been conducted in the lab, and reasonably so; it is difficult to control testing conditions of wild animals. There are several reasons why copying may be more prevalent in animals tested in the wild. It is possible that species or populations that are easily tested in the wild also happen to be those that most readily use social information in mate choice. It's also possible that mate-choice copying effects are intensified in situations typical of wild populations. For example, the possible presence of predators could make slower mate choices risky, favoring copying behavior (Gibson and Höglund, 1992). Further, females in the wild may be faced with more mating options compared to the typical dichotomous choice in captivity, and thus rely more on the observed choices of other females to inform their own mating decisions. Similarly, female competition for mates may be stronger in the wild, driving the need to make timely mate-choice decisions. Copying the choice of another female may take less time than acquiring direct information about the quality of a mate. Free-living females may use matechoice copying more frequently as a time-saving strategy to ensure mating opportunities are not missed. Differences in food availability between lab and field populations may also affect results. However, in one systematic test of this effect, guppies were more likely to copy mate choices when they were satiated, not when hungry as predicted if mate-choice copying reduces decision time (Dugatkin and Godin, 1998). There remains much to be gained both from studies in the wild of species documented to copy mate choices in the lab, and from lab studies that systematically test how environmental factors modify the occurrence of mate-choice copying.

Not unexpectedly, our dataset had a high level of heterogeneity. In the random effects model that accounted for only phylogeny, repeated measures of individual species, and multiple effect sizes derived from the same study, the vast majority $(75 \%)$ of variance in the data was attributed to differences among species. However, including moderators of observer experience, relative age of the model female, male attractiveness, and test conditions explained species-level variance, indicating differences that appeared to be explained by species identity were more appropriately attributed to combinations of these fixed effects. Likewise, the mixed and random effects models did not differ in their short-term predictive ability (as indicated by their DIC values), but the mixed model indentified factors that explained virtually all the heterogeneity among the species represented in our metadataset. However, this pattern furthermore highlights the trend that studies assessing the same species often apply similar testing conditions. For example, all Drosophila studies were conducted under laboratory conditions and using virgin focal females. The Trinidadian guppy remains the best-studied species for understanding mate-choice copying and is the only species in our dataset for which effects of all moderators have been investigated.

The reported differences between levels of the explanatory factors are likely underestimated, specifically for male attractiveness and observer experience, as one of the two compared levels for each factor included unavoidable uncertainty. For example, for classification of observer experience, there was no ambiguity when studies used virgin female observers, but when observers were drawn from a population of unknown age or experience (e.g., wild studies, mixed-sex tanks), the testing group almost certainly included a mix of individuals, some of which might have been virgins or females with relatively low sexual experience. Likewise, for tests of mate attractiveness, studies employing experimental reversals were compared those in which researchers assigned a model female to one of two males at random or allowed the model to choose (i.e., non-reversals). Males paired with models 
in non-reversal studies were not necessarily more attractive than the unpaired males. However, we assumed that they were on average more attractive than paired males in the reversal trails, which were known to have been previously rejected by female observers. We therefore predict that the true difference in effect sizes of the occurrence of mate-choice copying between less attractive and more attractive males is larger than reported.

The phylogenetic signal of the strength of mate-choice copying was virtually non-existent, indicating that this behavior is taxonomically widespread. Likewise, mate-choice copying was not consistent in several closely related species, e.g., there is strong support for the occurrence of mate-choice copying in Drosophila melanogaster (Germain et al., 2016; Danchin et al., 2018; Nöbel et al., 2018), but tests in Drosophila serrata found no copying (Auld et al., 2009). However, studies that met our criteria of providing individual-level counts of mating choices represented only 17 total species. Several prominent clades for which social learning is evident in other contexts were not represented here, including mammals (Box and Gibson, 1999), amphibians (Ferrari et al., 2007), and cephalopods (Fiorito and Scotto, 1992). This lack can be attributed in part to our exclusion of studies that measured mate choice in a manner other than discrete choices. Conducting an analysis of effect sizes derived from differences in means (e.g., differences in the means of time spent near competing males) would broaden taxonomic representation. However, low taxonomic representation of some clades reflects the lingering lack of tests in those taxa. While it makes sense that highly social animals would be more likely to transfer information among conspecifics during matechoice, studies robustly indicating the occurrence of mate-choice copying in Drosophila melanogaster and in wolf spiders indicate that complex sociality is not required for mate-choice copying to occur, and that a phylogenetic interpretation of the pattern of mate-choice copying across taxa suggests that it occurred in the common ancestor of all Nephrozoa (Fowler-Finn et al., 2015; Danchin et al., 2018; Monier et al., 2018; Nöbel et al., 2018). We suggest that mate-choice copying is not an isolated and discreetly evolved trait within social animals, but rather one of many manifestations of an underlying evolved cognitive ability to observe and copy the choices of others. If mate choice copying results from the same cognitive processes that underlie conspecific cueing in foraging and habitat choices, the cost:benefit ratio of copying may be quite low.

The results of this meta-analysis suggest several areas for future work. First, as noted above, it would be interesting to expand the meta-analysis framework to studies that measured mate-choice copying in different ways. While we restricted our meta-analysis to experiments that quantified the number of individual female choices, there are several valid ways of measuring mate-choice copying (or its assumptions). Most notably, we did not include studies that relied on time spent near a male following or during the presence of a model (e.g., Höglund et al., 1995), though we consider this a valid alternative to quantifying discrete choices. Expanding the types of component analyses included in a meta-analysis of copying effects may allow investigation of hypothesized mate-choice copying effects that we were unable to address here. For example, is mate-choice copying of preference for specific individuals stronger than generalized copying of socially preferred males' phenotypes? Only a few of the studies included here tested for generalized copying behavior rather than preference for the specific individual preferred by other females. These reported that copying was indeed a phenotype-general phenomenon. For example, zebra finches (Taeniopygia guttata) copy choices for leg band color in general, not only for individual males (Swaddle et al., 2005). In the dataset used here, we were unable to test whether the occurrence of generalized phenotype copying was robust across studies, or whether the strength of copying effects was weaker (or stronger) in these generalized situations. Additionally, future studies should test the assumption that mate-choice copying decreases costs of independent choice, for example by decreasing decision time during mate choice. We were unable to assess effects of mating system on mate choice copying, as nearly all tested species were socially polygamous. It would be interesting to investigate whether mate-choice copying varies with different types of polygamy, as well-testing for effects in an expanded sample of monogamous species. Finally, several studies noted that the amount and consistency of information can influence the expression of copying behavior. When multiple demonstrators reinforce a non-preferred choice, mate-choice copying is stronger (Dugatkin, 1998; Drullion and Dubois, 2008). Likewise, when social information is inconsistent, females are less likely to copy (Drullion and Dubois, 2008). These effects were not tested broadly enough in our dataset to include as factors in this meta-analysis, but represent interesting avenues for future work.

Not unexpectedly, we detected significant publication bias, especially among studies with relatively small sample sizes. Because mate-choice copying influences mating decisions, it has the potential to influence patterns of sexual selection. Therefore, it is important to understand when copying is and is not a factor. We hope that this report will encourage publication of results rejecting as well as supporting the occurrence of mate-choice copying behavior. Indeed, our results indicate that mate-choice copying should not necessarily always be present (as indicated by the broad $95 \%$ prediction interval of the overall effect). The average effect sizes reported here should be useful in power analyses for planning and publishing future work on copying behavior, regardless of the study's outcome.

The support for a robust effect of mate-choice copying on mating decisions across taxa indicates that this phenomenon is a widespread part of mating behavior, particularly in wild systems, though it remains to be incorporated into much current research investigating the process of sexual selection by mate-choice. This meta-analysis identified several contexts-inexperienced observers, information favoring less attractive males, and animals in free-living situations-in which mate-choice copying is more likely to occur, an important step toward predicting its evolutionary consequences (Verzijden et al., 2012). Understanding the 
strength and moderators of mate-choice copying effects will be an important part of more clearly incorporating this phenomenon into our understanding of social behavior and sexual selection.

\section{AUTHOR CONTRIBUTIONS}

Both authors contributed equally to the final manuscript. ED conceived the analysis and planned the conceptual framework. BJ conducted statistical analyses and developed figures. Both authors drafted and edited the manuscript.

\section{FUNDING}

ED and BJ were supported by NSF IOS-1453408 to ED.

\section{REFERENCES}

Adams, D. C. (2008). Phylogenetic meta-analysis. Evolution 62, 567-572. doi: 10.1111/j.1558-5646.2007.00314.x

Alonzo, S. H. (2008). Female mate choice copying affects sexual selection in wild populations of the ocellated wrasse. Anim. Behav. 75, 1715-1723. doi: 10.1016/j.anbehav.2007.09.031

Amlacher, J., and Dugatkin, L. A. (2005). Preference for older over younger models during mate-choice copying in young guppies. Ethol. Ecol. Evol. 17, 161-169. doi: 10.1080/08927014.2005.9522605

Applebaum, S. L., and Cruz, A. (2000). The role of mate-choice copying and disruption effects in mate preference determination of Limia perugiae (Cyprinodontiformes, Poeciliidae). Ethology 106, 933-944. doi: 10.1046/j.1439-0310.2000.00607.x

Auld, H. L., and Godin, J.-G. J. (2015). Sexual voyeurs and copiers: social copying and the audience effect on male mate choice in the guppy. Behav. Ecol. Sociobiol. 69, 1795-1807. doi: 10.1007/s00265-015-1992-z

Auld, H. L., Punzalan, D., Godin, J.-G. J., and Rundle, H. D. (2009). Do female fruit flies (Drosophila serrata) copy the mate choice of others? Behav. Proc. 82, 78-80. doi: 10.1016/j.beproc.2009.03.004

Bierbach, D., Kronmarck, C., Hennige-Schulz, C., Stadler, S., and Plath, M. (2011). Sperm competition risk affects male mate choice copying. Behav. Ecol. Sociobiol. 65, 1699-1707. doi: 10.1007/s00265-011-1177-3

Blomberg, S. P., Garland, J. R. T., and Ives, A.R. (2003). Testing for phylogenetic signal in comparative data: behavioral traits are more labile. Evolution 57, 717-745. doi: 10.1111/j.0014-3820.2003.tb00285.x

Box, H. O., and Gibson, K. R. (eds.). (1999). Mammalian Social Learning: Comparative and Ecological Perspectives. Cambridge: Cambridge University Press.

Briggs, S. E., Godin, J.-G. J., and Dugatkin, L. A. (1996). Mate-choice copying under predation risk in the Trinigadian guppy (Poecilia reticulata). Behav. Ecol. 7, 151-157. doi: 10.1093/beheco/7.2.151

Brooks, R. (1996). Copying and the repeatability of mate choice. Behav. Ecol. Sociobiol. 39, 323-329. doi: 10.1007/s002650050296

Brooks, R. (1999). Mate choice copying in guppies: females avoid the place where they saw courtship. Behaviour 136, 411-412. doi: 10.1163/156853999501397

Dagaeff, A. C., Pocheville, A., Nöbel, S., Loyau, A., Isabel, G., and Danchin, E. (2016). Drosophila mate copying correlates with atmospheric pressure in a speed learning situation. Anim. Behav. 121, 163-174. doi: 10.1016/j.anbehav.2016.08.022

Danchin, E., Giraldeau, L. A., Valone, T., and Wagner, R. (2004). Public information: from nosy neighbors to cultural evolution. Science 305, 487-491. doi: $10.1126 /$ science. 1098254

Danchin, E., Nöbel, S., Pocheville, A., Dagaeff, A.-C., Demay, L., Alphand, M., et al. (2018). Cultural flies: conformist social learning in fruitflies predicts long-lasting mate-choice traditions. Science 362, 1025-1030. doi: $10.1126 /$ science.aat 1590

\section{ACKNOWLEDGMENTS}

We thank editor Christina Riehl and Mark Elgar for hosting the special issue on mechanism of communication and recognition in social evolution. We thank Adam Smith for advice with statistical interpretation, and K. Witte and E. Huchard for comments that improved the final version of this manuscript. We are also grateful to Duane McKenna for his expert guidance on available resources for constructing ultrametric trees.

\section{SUPPLEMENTARY MATERIAL}

The Supplementary Material for this article can be found online at: https://www.frontiersin.org/articles/10.3389/fevo. 2019.00390/full\#supplementary-material

Doucet, S. M., Yezerinac, S. M., and Montgomerie, R. (2004). Do female zebra finches (Taeniopygia guttata) copy each other's mate preferences? Canad. J. Zool. 82, 1-7. doi: 10.1139/z03-210

Drullion, D., and Dubois, F. (2008). Mate-choice copying by female zebra finches, Taeniopygia guttata: what happens when model females provide inconsistent information? Behav. Ecol. Sociobiol. 63, 269-276. doi: 10.1007/s00265-008-0658-5

Dubois, F., Drullion, D., and Witte, K. (2011). Social information use may lead to maladaptive decisions: a game theoretic model. Behav. Ecol. 23, 225-231. doi: 10.1093/beheco/arr179

Dugatkin, L. A. (1992). Sexual selection and imitation: females copy the mate choice of others. Am. Nat. 139, 1384-1389. doi: 10.1086/285392

Dugatkin, L. A. (1996). Interface between culturally based preferences and genetic preferences: female mate choice in Poecilia reticulata. Proc. Natl. Acad. Sci. U.S.Am. 93, 2770-2773. doi: 10.1073/pnas.93.7.2770

Dugatkin, L. A. (1998). Genes, copying, and female mate choice: shifting thresholds. Behav. Ecol. 9, 323-327. doi: 10.1093/beheco/9.4.323

Dugatkin, L. A., Druen, M. W., and Godin, J. G. (2003). The disruption hypothesis does not explain mate-choice copying in the guppy (Poecilia reticulata). Ethology 109, 67-76. doi: 10.1046/j.1439-0310.2003.00851.x

Dugatkin, L. A., and Godin, J. G. (1992). Reversal of female mate choice by copying in the guppy (Poecilia reticulata). Proc. Biol. Sci. 249, 179-184. doi: $10.1098 / \mathrm{rspb} .1992 .0101$

Dugatkin, L. A., and Godin, J. G. (1993). Female mate copying in the guppy (Poecilia reticulata): age-dependent effects. Behav. Ecol. 4, 289-292. doi: 10.1093/beheco/4.4.289

Dugatkin, L. A., and Godin, J. G. (1998). Effects of hunger on mate-choice copying in the guppy. Ethology 104, 194-202. doi: 10.1111/j.1439-0310.1998.tb00062.x

Duval, S. (2005). "The trim and fill method" in Publication Bias in Meta-analysis: Prevention, Assessment and Adjustments, eds H. R. Rothstein, A. J. Sutton, and M. Borenstein. (Chichester: Wiley), 127-144.

Duval, S., and Tweedie, R. (2000). Trim and fill: a simple funnel-plot-based method of testing and adjusting for publication bias in meta-analysis. Biometrics 56, 455-463. doi: 10.1111/j.0006-341X.2000.00455.x

Ferrari, M. C. O., Messier, F., and Chivers, D. P. (2007). First documentation of cultural transmission of predator recognition by larval amphibians. Ethology 113, 621-627. doi: 10.1111/j.1439-0310.2007.01362.x

Fiorito, G., and Scotto, P. (1992). Observational learning in Octopus vulgaris. Science 256:545. doi: 10.1126/science.256.5056.545

Forsgren, E., Karlsson, A., and Kvarnemo, C. (1996). Female sand gobies gain direct benefits by choosing males with eggs in their nests. Behav. Ecol. Sociobiol. 39, 91-96. doi: 10.1007/s0026500 50270

Fowler-Finn, K. D., Sullivan-Beckers, L., Runck, A. M., and Hebets, E. A. (2015). The complexities of female mate choice and male polymorphisms: Elucidating the role of genetics, age, and mate-choice copying. Curr. Zool. 61, 1015-1035. doi: 10.1093/czoolo/61.6.1015 
Freckleton, R. P., Harvey, P. H., and Pagel, M. (2002). Phylogenetic analysis and comparative data: a test and review of evidence. Am. Nat. 160, 712-726. doi: $10.1086 / 343873$

Freed-Brown, G., and White, D. J. (2009). Acoustic mate copying: female cowbirds attend to other females' vocalizations to modify their song preferences. Proc. Biol. Sci. 276, 3319-3325. doi: 10.1098/rspb.2009.0580

Galef, B. G., and Giraldeau, L.-A. (2001). Social influences on foraging in vertebrates: causal mechanisms and adaptive functions. Anim. Behav. 61, 3-15. doi: 10.1006/anbe. 2000.1557

Germain, M., Blanchet, S., Loyau, A., and Danchin, E. (2016). Mate-choice copying in Drosophila melanogaster: impact of demonstration conditions and malemale competition. Behav. Proc. 125, 76-84. doi: 10.1016/j.beproc.2016.02.002

Gibson, R. M., and Höglund, J. (1992). Copying and sexual selection. Trends Ecol. Evol. 7, 229-232. doi: 10.1016/0169-5347(92)90050-L

Gierszewski, S., Baker, D., Muller, K., Hutwohl, J. M., Kuhnert, K. D., and Witte, K. (2018a). Using the FishSim animation toolchain to investigate fish behavior: a case study on mate-choice copying in sailfin mollies. J. Vis. Exp. 141:e58435. doi: $10.3791 / 58435$

Gierszewski, S., Keil, M., and Witte, K. (2018b). Mate-choice copying in sailfin molly females: public information use from long-distance interactions. Behav. Ecol. Sociobiol. 72:26. doi: 10.1007/s00265-018-2441-6

Godin, J.-G., Herdman, E. J. E., and Dugatkin, L. A. (2005). Social influences on female mate choice in the guppy, Poecilia reticulata: generalized and repeatable trait-copying behaviour. Anim. Behav. 69, 999-1005. doi: 10.1016/j.anbehav.2004.07.016

Godin, J.-G. J., and Hair, K. (2009). Mate-choice copying in free-ranging Trinidadian guppies (Poecilia reticulata. Behaviour 146, 1443-1461. doi: 10.1163/156853909X441014

Goldschmidt, T., Bakker, T. C. M., and Feuth-de Bruijn, E. (1993). Selective copying in mate choice of female sticklebacks. Anim. Behav. 45, 541-547. doi: 10.1006/anbe.1993.1064

Gouda-Vossos, A., Nakagawa, S., Dixson, B. J. W., and Brooks, R. C. (2018). Mate choice copying in humans: a systematic review and meta-analysis. Adap. Hum. Behav. Physiol. 4, 364-386. doi: 10.1007/s40750-018-0099-y

Goulet, D. (1997). Reproductive behavior and spawning success of female Amblyglyphidodon leucogaster (Pisces: Pomacentridae) from the Red Sea. Environ. Biol. Fishes 50, 49-60. doi: 10.1023/A:1007350601234

Goulet, D., and Goulet, T. L. (2006). Nonindependent mating in a coral reef damselfish: evidence of mate choice copying in the wild. Behav. Ecol. 17, 998-1003. doi: 10.1093/beheco/arl032

Grant, J. W. A., and Green, L. D. (1996). Mate copyingversus preference for actively courting males by female Japanese medaka (Oryzias latipes). Behav. Ecol. 7, 165-167. doi: 10.1093/beheco/7.2.165

Hadfield, J. (2010). MCMC methods for multi-response generalized linear mixed models: the MCMCglmm R package. J. Statist. Softw. 33, 1-22. doi: $10.18637 /$ jss.v033.i02

Hadfield, J. D., and Nakagawa, S. (2010). General quantitative genetic methods for comparative biology: phylogenies, taxonomies and multi-trait models for continuous and categorical characters. J. Evol. Biol. 23, 494-508. doi: $10.1111 / j .1420-9101.2009 .01915 . x$

Hedges, L. V., and Vevea, J. L. (1998). Fixed- and random-effects models in meta-analysis. Psychol. Methods 3, 486-504. doi: 10.1037/1082-989X.3. 4.486

Henderson, C. R. (1976). A simple method for computing the inverse of a numerator relationship matrix used in prediction of breeding values. Biometrics 32, 69-83. doi: $10.2307 / 2529339$

Higgins, J. P. T., and Thompson, S. G. (2002). Quantifying heterogeneity in a meta-analysis. Statist. Med. 21, 1539-1558. doi: 10.1002/sim.1186

Higgins, J. P. T., Thompson, S. G., Deeks, J. J., and Altman, D. G. (2003). Measuring inconsistency in meta-analyses. BMJ 327, 557-560. doi: $10.1136 / \mathrm{bmj} .327 .7414 .557$

Hill, S. E., and Ryan, M. J. (2006). The role of model female quality in the mate choice copying behaviour of sailfin mollies. Biol. Lett. 2, 203-205. doi: 10.1098/rsbl.2005 .0423

Höglund, J., Alatalo, R. V., Gibson, R. M., and Lundberg, A. (1995). Mate-choice copying in black grouse. Anim. Behav. 49, 1627-1633. doi: 10.1016/0003-3472(95)90085-3
Hoppitt, W., and Laland, K. N. (2008). "Social processes influencing learning in animals: a review of the evidence," in Advances in the Study of Behavior, eds H. J. Brockmann, T. J. Roper, M. Naguib, K. E. Wynne-Edwards, C. Barnard, and J. C. Mitani (Burlington, MA: Academic Press), 105-165.

Howard, R. D., Martens, R. S., Innis, S. A., Drnevich, J. M., and Hale, J. (1998). Mate choice and mate competition influence male body size in Japanese medaka. Anim. Behav. 55, 1151-1163. doi: 10.1006/anbe.1997.0682

Kendal, R., Hopper, L. M., Whiten, A., Brosnan, S. F., Lambeth, S. P., Schapiro, S. J., et al. (2015). Chimpanzees copy dominant and knowledgeable individuals: implications for cultural diversity. Evol. Hum. Behav. 36, 65-72. doi: 10.1016/j.evolhumbehav.2014.09.002

Kniel, N., Dürler, C., Hecht, I., Heinbach, V., Zimmermann, L., and Witte, K. (2015). Novel mate preference through mate-choice copying in zebra finches: sexes differ. Behav. Ecol. 26, 267-655. doi: 10.1093/beheco/aru241

Kumar, S., Stecher, G., Suleski, M., and Hedges, S. B. (2017). TimeTree: a resource for timelines, timetrees, and divergence times. Mol. Biol. Evol. 34, 1812-1819. doi: $10.1093 / \mathrm{molbev} / \mathrm{msx} 116$

Lafleur, D. L., Lozano, G. A., and Sclafani, M. (1997). Female mate-choice copying in guppies, Poecilia reticulata: a re-evaluation. Anim. Behav. 54, 579-586. doi: 10.1006/anbe.1996.0452

Lajeunesse, M. J. (2009). Meta-analysis and the comparative phylogenetic method. Am. Nat. 174, 369-381. doi: 10.1086/603628

Lee, A. E., Ounsley, J. P., Coulson, T., Rowcliffe, J. M., and Cowlishaw, G. (2016). Information use and resource competition: an integrative framework. Proc. Biol. Sci. 283:20152550. doi: 10.1098/rspb.2015.2550

Lill, A. (1974). Sexual behavior of the lek-forming white-bearded manakin (Manacus manacus trinitatis Hartert). Z. Tierpsychol. 36, 1-36. doi: 10.1111/j.1439-0310.1974.tb02126.x

Loukola, O. J., Seppänen, J.-T., and Forsman, J. T. (2012). Intraspecific social information use in the selection of nest site characteristics. Ani. Behav. 83, 629-633.doi: 10.1016/j.anbehav.2011.12.004

Lynch, M. (1991). Methods for the analysis of comparative data in evolutionary biology. Evolution 45, 1065-1080. doi: 10.1111/j.1558-5646.1991.tb04375.x

Matsumoto, Y., and Takegaki, T. (2013). Female mate choice copying increases egg survival rate but does not reduce mate-sampling cost in the barred-chin blenny. Ani. Behav. 86, 339-346. doi: 10.1016/j.anbehav.2013.05.024

Mery, F., Varela, S. A. M., Danchin, É., Blanchet, S., Parejo, D., Coolen, I., et al. (2009). Public versus personal information for mate copying in an invertebrate. Curr. Biol. 19, 730-734. doi: 10.1016/j.cub.2009.02.064

Milner, R., Jennions, M., and Backwell, P. (2011). Non-independent mate choice in a fiddler crab: A case of stimulus enhancement. Behav. Ecol. Sociobiol. 65, 1419-1424. doi: 10.1007/s00265-011-1152-z

Monier, M., Nöbel, S., Danchin, E., and Isabel, G. (2019). Dopamine and serotonin are both required for mate-copying in Drosophila melanogaster. Front. Behav. Neurosci. 12:334. doi: 10.3389/fnbeh.2018.00334

Monier, M., Nöbel, S., Isabel, G., Danchin, E., and David, B. (2018). Effects of a sex ratio gradient on female mate-copying and choosiness in Drosophila melanogaster. Curr. Zool. 64, 251-258. doi: 10.1093/cz/zoy014

Munger, L., Cruz, A., and Applebaum, S. (2004). Mate choice copying in female humpback limia (Limia nigrofasciata, Family Poeciliidae). Ethology 110, 563-573. doi: 10.1111/j.1439-0310.2004.00991.x

Nakagawa, S., and Santos, E. S. A. (2012). Methodological issues and advances in biological meta-analysis. Evol. Ecol. 26, 1253-1274. doi: 10.1007/s10682-012-9555-5

Nöbel, S., Danchin, E., and Isabel, G. (2018). Mate-copying for a costly variant in Drosophila melanogaster females. Behav. Ecol. 29, 1150-1156. doi: 10.1093/beheco/ary095

Nordell, S. E., and Valone, T. J. (1998). Mate choice copying as public information. Ecol. Lett. 1, 74-76. doi: 10.1046/j.1461-0248.1998.00025.x

Pagel, M. (1999). Inferring the historical patterns of biological evolution. Nature 401, 877-884. doi: 10.1038/44766

Patriquin-Meldrum, K. J., and Godin, J.-G. J. (1998). Do female three-spined sticklebacks copy the mate choice of others? Am. Nat. 151, 570-577. doi: $10.1086 / 286142$

Peters, J. L., Sutton, A. J., Jones, D. R., Abrams, K. R., and Rushton, L. (2007). Performance of the trim and fill method in the presence of publication bias and between-study heterogeneity. Statist. Med. 26, 4544-4562. doi: $10.1002 /$ sim. 2889 
Pruett-Jones, S. (1992). Independent versus nonindependent mate choice: do females copy each other? Am. Nat. 140, 1000-1009. doi: 10.1086/285452

R Core Team (2019). R: A Language and Environment for Statistical Computing. Vienna: R Foundation for Statistical Computing. Available online at: https:// www.R-project.org/

Riley, R. D., Higgins, J. P. T., and Deeks, J. J. (2011). Interpretation of random effects meta-analyses. Br. Med. J. 342:d549. doi: 10.1136/bmj.d549

Rosenthal, R. (1979). The file drawer problem and tolerance for null results. Psychol. Bull. 86, 638-641. doi: 10.1037/0033-2909.86.3.638

Schlupp, I., and Ryan, M. J. (1997). Male Sailfin mollies (Poecilia latipinna) copy the mate choice of other males. Behav. Ecol. 8, 104-107. doi: 10.1093/beheco/8.1.104

Schwarzer, G. (2007). meta: an R package for meta-analysis. $R$ News 7, 40-45. doi: 10.1007/978-3-319-21416-0

Senior, A. M., Grueber, C. E., Kamiya, T., Lagisz, M., O’Dwyer, K., Santos, E. S. A., et al. (2016). Heterogeneity in ecological and evolutionary meta-analyses: its magnitude and implications. Ecology 97, 3293-3299. doi: 10.1002/ecy.1591

Slagsvold, T., and Viljugrein, H. (1999). Mate choice copying versus preference for actively displaying males by female pied flycatchers. Anim. Behav. 57, 679-686. doi: 10.1006/anbe.1998.0996

Spiegelhalter, D. J., Best, N. G., Carlin, B. P., and van der Linde, A. (2014). The deviance information criterion: 12 years on. J. R. Statist. Soc. B 76, 485-493. doi: $10.1111 /$ rssb.12062

Stiver, K. A., and Alonzo, S. H. (2010). Alloparental care increases mating success. Behav. Ecol. 22, 206-211. doi: 10.1093/beheco/arq186

Sutton, A. (2009). "Publication bias," in The Handbook of Research Synthesis and Meta-analysis, eds H. Cooper, L. Hedges, and J. Valentine (New York, NY: Russell Sage Foundation), 435-452.

Swaddle, J. P., Cathey, M. G., Correll, M., and Hodkinson, B. P. (2005). Socially transmitted mate preferences in a monogamous bird: a non-genetic mechanism of sexual selection. Proc. Biol. Sci. 272, 1053-1058. doi: 10.1098/rspb.2005.3054

Vakirtzis, A. (2011). Mate choice copying and nonindependent mate choice: a critical review. Ann. Zool. Fenn. 48, 91-107. doi: 10.5735/086.048.0202

Valone, T. J., and Templeton, J. J. (2002). Public information for the assessment of quality: a widespread social phenomenon. Philos. Trans. R. Soc. Lond. B. Biol. Sci. 357, 1549-1557. doi: 10.1098/rstb.2002.1064

Varela, S. A. M., Matos, M., and Schlupp, I. (2018). The role of matechoice copying in speciation and hybridization. Biol. Rev. 93, 1304-1322. doi: $10.1111 /$ brv. 12397
Verzijden, M. N., ten Cate, C., Servedio, M. R., Kozak, G. M., Boughman, J. W., and Svensson, E. I. (2012). The impact of learning on sexual selection and speciation. Trends Ecol. Evol. 27, 511-519. doi: 10.1016/j.tree.2012. 05.007

Vukomanovic, J., and Rodd, F. H. (2007). Size-dependent female mate copying in the guppy (Poecilia reticulata): large females are role models but small ones are not. Ethology 113, 579-586. doi: 10.1111/j.1439-0310.2007. 01343.x

Wade, M. J., and Pruett-Jones, S. G. (1990). Female copying increases the variance in male mating success. Proc. Natl. Acad. Sci. U.S.A. 87, 5749-5753. doi: 10.1073/pnas.87.15.5749

Waynforth, D. (2007). Mate choice copying in humans. Hum. Nat. 18, 264-271. doi: 10.1007/s12110-007-9004-2

White, D. J., and Galef, B. G. (1999). Social effects on mate choices of male Japanese quail, Coturnix japonica. Anim. Behav. 57, 1005-1012. doi: 10.1006/anbe.1998.1059

Widemo, M. S. (2005). Male but not female pipefish copy mate choice. Behav. Ecol. 17, 255-259. doi: 10.1093/beheco/arj021

Wiley, R. H. (1973). Territoriality and non-random mating in sage grouse, Centrocercus urophasianus. Ani. Behav. Monogr. 6, 85-169. doi: 10.1016/0003-3472(73)90004-3

Witte, K., Kniel, N., and Kureck, I. M. (2015). Mate-choice copying: Status quo and where to go. Curr. Zool. 61, 1073-1081. doi: 10.1093/czoolo/61.6.1073

Witte, K., and Noltemeier, B. (2002). The role of information in mate-choice copying in female sailfin mollies (Poecilia latipinna). Behav. Ecol. Sociobiol. 52, 194-202. doi: 10.1007/s00265-002-0503-1

Witte, K., and Ryan, M. J. (2002). Mate choice copying in the sailfin molly, Poecilia latipinna, in the wild. Anim. Behav. 63, 943-949. doi: 10.1006/anbe.2001.1982

Conflict of Interest: The authors declare that the research was conducted in the absence of any commercial or financial relationships that could be construed as a potential conflict of interest.

Copyright (c) 2019 Jones and DuVal. This is an open-access article distributed under the terms of the Creative Commons Attribution License (CC BY). The use, distribution or reproduction in other forums is permitted, provided the original author(s) and the copyright owner(s) are credited and that the original publication in this journal is cited, in accordance with accepted academic practice. No use, distribution or reproduction is permitted which does not comply with these terms. 